\title{
BRIDGING THE GAP BETWEEN RISK ANALYSIS AND SECURITY POLICIES
}

\section{Using Requirement Engineering Techniques}

\author{
Paul Gaunard, Eric Dubois \\ Centre de Recherche Public Henri Tudor (CRP-HT) \\ Centre d'Innovation par les Technologies de l'Information (CITI) \\ 6, rue Coudenhove-Kalergi. 1359 Luxembourg \\ \{paul.gaunard, eric.dubois\} (a) undor:lu
}

\begin{abstract}
In the IT security management process, a methodological gap exists between the results of a risk analysis, the development of adequate security policies and the selection of appropriate operational controls. We believe that a number of methods and techniques developed by the Requirement Engineering community, and goal requirements modelling in particular, can be useful to bridge this gap by providing modelling frameworks that might support those processes.
\end{abstract}

Key words: IT Security, Risk Management, Requirement Engineering methods and modelling techniques

\section{INTRODUCTION}

IT insecurity results from a particular set of risks that should be properly evaluated and then minimized to a level acceptable regarding the organisation's goals and constraints.

While most of the bricks needed for the management of IT security exist, there are still some methodological gaps to be filled to achieve a rational process that will minimize the actual subjectivity involved in the translation of the risk analysis results into appropriate security policies and decisions for the selection of appropriate controls.

The original version of this chapter was revised: The copyright line was incorrect. This has been corrected. The Erratum to this chapter is available at DOI: 10.1007/978-0-387-35691-4_52 


\section{CONCEPTS OF A RISK-BASED SECURITY MANAGEMENT PROCESS}

The information security management process is based on risk management principles and mixes risk analysis methods with technical and organisational practices. Although many variants exists, the process is almost always based on the following steps $[1,2,3]$ :

- an analysis of the organisational context, and in particular, of goals set by the stakeholders and constraints imposed on the organisation;

- an identification of the assets (also called resources) to be protected;

- a security risk analysis, identifying threats vulnerabilities and impacts;

- the development of a security policy for the risk reduction;

- the selection, implementation and management of operational controls.

\section{REQUIREMENT ENGINEERING AND RISK MANAGEMENT}

Making explicit goals and constraints is vital to ensure a proper policy development and controls selection. The Requirement Engineering (RE) community has done a lot of work to provide adequate methodologies and tools to enhance the software requirement elicitation process, based on the integration of those goals and constraints. These tools have proven useful in various situations, even outside the software world.

Recent researches $[4,5,6,7]$ also present some attempts to integrate IT security concepts and risk management methods into the requirement engineering process. In the line of these efforts, we propose some extensions to a well established RE modelling framework in order to capture and reason on risks and security concepts.

Our proposal is based upon a modelling framework inspired from the Goal Requirement Language (GRL) [8], developed by the University of Toronto. According to its authors, GRL is "a language for supporting goaloriented modelling and reasoning of requirement, based on the merge of two previously studied frameworks, namely:

- the NFR framework [9], dealing with non-functional requirements;

- the I* $[10]$ framework, an agent oriented modelling framework.

Through several experiences and case studies, the GRL approach has been proven successful in helping in understanding organizational situations, in identifying stakeholders' goals and in reasoning about requirements alternatives. 


\section{ILLUSTRATION}

Let's illustrate (fig.1) our proposal on a basic example presenting security problems and potential solutions associated to a database for which goals like confidentiality, integrity and availability are required.

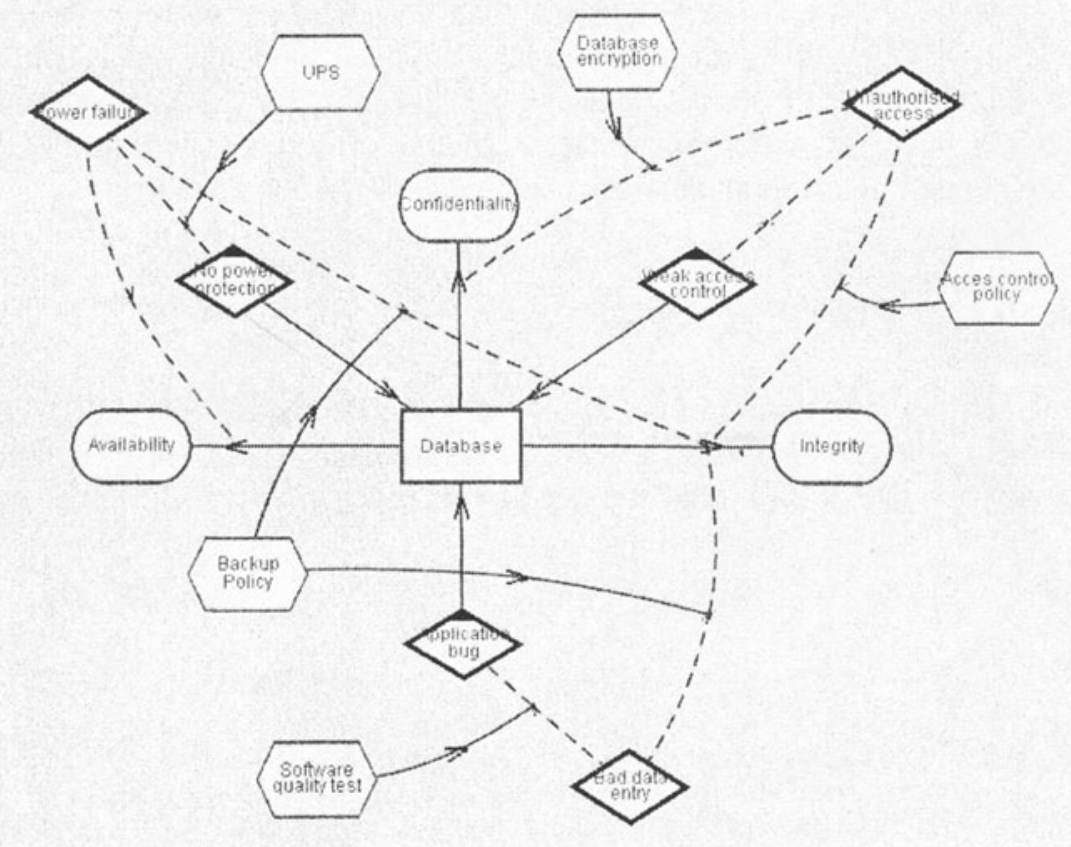

Figure 1. Database confidentiality, integrity and availability.

The database, modelled by a rectangle at the centre of the model, is a resource we wish to protect. Around it, our security goals are modelled by rounded rectangle. The database is affected by various vulnerabilities, like an application bug, a lack of power failure protection and weak access control, modelled by diamonds with black upper corners. These vulnerabilities can be exploited by various threats, modelled by diamonds, to results into various impacts modelled by dashed arrows linking those threats to the links between resources and related goals. Various controls and counter-measures, like UPS, backup, access control and encryption can be applied to counter those identified risks. entry, thus reducing the integrity risk associated to bad data entries.

This example emphasises the importance to get the "big picture" to fully understand the ins and outs of IT security risks, since many solutions exists for a given problems and one solution might be useful to several problems. We thus believe that such modelling framework, including various GRL 
concepts, would provide visual support helping practitioners during the security policy and control selection processes.

\section{CONCLUSION}

In this paper, we have suggested that the requirement engineering community had developed models from which various modelling ideas could be reused within the IT security management process. The next step in our research would be to determine the exact semantics required to build efficient models and to evaluate their practicability in real situations.

\section{ACKNOWLEDGEMENTS}

The work is partially supported by the Research National Fund of Luxembourg (Acces-PME project). Part of the research is performed within the context of the LIASIT (Luxembourg International Advanced Studies in Information Technologies) Institute.

\section{REFERENCES}

1. Stoneburner, G., Goguen, A., Feringa, A. Risk Management Guide for Information Technology Management, National Institue of Standard and Technology, October 2001

2. Octave Critical Threat, Asset and Vulnerability Evaluation (OCTAVE), Carnegie Mellon Software Engineering Institute, June 1999

3. Expression des Besoins et Identification des Objectifs de Sécurité (EBIOS), Service Central de la Sécurité des Systèmes d'Information, Juin 1997

4. Chung, L.,"Dealing with Security Requirements During the Development of Information Systems,"; Proc. CAiSE 93, 5th Int. Conf. Advanced Information Systems Engineering, Paris, France. Berlin: Springer-Verlag. 1993, pp. 234-251

5. Eames, D. and Moffett J. D.,(1999), "The Integration of Safety and Security Requirements", Safecomp'99, 27-29 Sept 1999, Toulouse, France

6. Antón, A. I., Earp, J. B., "Strategies for Developing Policies and Requirements for Secure Electronic Commerce Systems", Ist ACM Workshop on Security and Privacy in ECommerce (CCS 2000), Athens, Greece, unnumbered pages, $1-4$ November 2000

7. Moffett, Johnatan. D. "Requirements and Policies", Position paper for Workshop on Policies in Distributed Systems, 15-17 November 1999, HP-Laboratories, Bristol, UK

8. Goal-oriented Requirement Language, http://www.cs.toronto.edu/km/GRL/, University of Toronto, Canada

9. Chung, L. Representing and Using Non-Functional Requirements: A Process-Oriented Approach, Ph.D. thesis, Department of Computer Science, U. of Toronto, 1993

10.Yu, E., Modelling Strategic Relationships for Process Reengineering, Ph.D. thesis, Department of Computer Science, U. of Toronto, 1995 